\title{
EKSTRAKSI DAN SINTESIS NANOSILIKA BERBASIS PASIR BANCAR DENGAN METODE BASAH
}

\author{
Munasir $^{1,2^{*}}$, Triwikantoro ${ }^{1}$, Moch.Zainuri ${ }^{1}$, Darminto ${ }^{1}$ \\ ${ }^{1}$ Program Studi Pascasarjana Fisika FMIPA-ITS, \\ Kampus ITS , Jl. Arief Rahman Hakim, Keputih-Sukolilo-Surabaya 60111 \\ ${ }^{2}$ Program Studi Fisika FMIPA-UNESA \\ Kampus UNESA, Jl. Ketintang Surabaya 60231 \\ *email: munasir09@mhs.physics.its.ac.id dan nasir1769@gmail.com
}

\begin{abstract}
The Purification and synthesis nanosilika extracts from quartz sand base material taken Bancar Tuban area ( north of the Island of Java-Indonesia) has been carried out in this study. Physically Tuban Bancar sand grains have a slightly rough shape and bright yellow. Sand Bancar has elements Si atoms (69\%Wt), and elements of the dominant impurity atoms is $\mathrm{Ca}(7.5 \% \mathrm{Wt})$ and $\mathrm{K}(4.8 \% W t)$. Diffraction pattern shows a dominant intesistas occurs at an angle $\left(2 \Theta \sim 26^{\circ}\right)$ the phase of quartz ( the most stable in nature). Size finely divided powder sand about 5-50 micrometers. Synthesis nanosilika based natural sand used wet method, which consists of two processes, namely: (1) sand powder processed by the hydrothermal method using alkaline compounds $(\mathrm{NaOH})$ with molarity $7 \mathrm{M}$, to obtain a clear solution of sodium silicate $\left(\mathrm{Na}_{2} \mathrm{O} . x \mathrm{SiO}_{2}\right)$, and (2) a solution of sodium silicate acts as prcursor processed by co-precipitation method, sodium silicate solution was titrated with $\mathrm{HCl} 2 \mathrm{M}$ (co-precipitation method) to obtain a slurry silicite $\mathrm{Si}(\mathrm{OH})_{4}$. The final product in the form of silica powder with amorphous and crystalline structures (quartz) ; purity (\%Wt Si) reached $95.7 \%$ and marfologi analysis showed that the $\mathrm{SiO} 2$ particles tend to form agglomeration and particle size of about $\sim 58 \mathrm{~nm}$
\end{abstract}

Key words: nanosilica, bancar sands, amorphous, quartz

\section{Abstrak}

Pemurnian, ekstrak dan sintesis nanosilika dari bahan dasar pasir kuarsa yang diambil di daerah Bancar Tuban (utara Pulau Jawa-Indonesia) telah dilakukan pada penelitian ini. Secara fisik pasir Bancar Tuban mempunyai bentuk butiran agak kasar dan berwarna kuning cerah. Pasir Bancar mempunyai unsur atom Si $(69 \% \mathrm{Wt})$, dan unsur atom pengotor dominan adalah $\mathrm{Ca}(7,5 \% \mathrm{wt})$ dan $\mathrm{K}(4,8 \% \mathrm{wt})$. Pola difraksinya menunjukan intesistas dominan terjadi pada sudut ( 2 theta) $\sim 26$ o, fase quartz (paling stabil di alam). Ukuran serbuk pasir yang telah dihaluskan sekitar 5-50 mikrometer. Sintesis nanosilika berbasis pasir alam digunakan metode basah, yang terdiri dari dua proses, yaitu: (1) serbuk pasir diproses dengan metode hidrotermal dengan menggunakan senyawa alkali $(\mathrm{NaOH})$ dengan molaritas $7 \mathrm{M}$, hingga diperoleh larutan bening sodium silikat $\left(\mathrm{Na}_{2} \mathrm{O} . x \mathrm{SiO}_{2}\right)$, dan (2) larutan sodium silikat berperan sebagai prcursor diproses dengan metode co-presipitasi, larutan sodium silikat dititrasi dengan $\mathrm{HCl} 2 \mathrm{M}$ hingga diperoleh bubur silicite $\mathrm{Si}(\mathrm{OH})_{4}$. Produk akhir berupa serbuk silika dengan struktur amorf dan kristal (quartz); kemurnian (\%Wt Si) mencapai 95,7\% dan analisis marfologi menunjukan bahwa partikel $\mathrm{SiO}_{2}$ cenderung membentuk aglomerasi dan ukuran partikel yang tidak beraglomerasi teramati berukuran sekitar $\sim 58 \mathrm{~nm}$.

Kata kunci: nanosilika, pasir bancar, amorf, quartz

\section{PENDAHULUAN}

Indonesia merupakan negara dengan potensi sumber daya alam yang melimpah. Potensi tersebut meliputi minyak, gas, dan bahan-bahan mineral. Diantara bahan-bahan mineral, terdapat bahan yang tergolong bahan oksida yang mempunyai potensi untuk pemanfaatan aplikasi teknologi tinggi seperti: $\mathrm{ZnO}, \mathrm{SiO}_{2}, \mathrm{MgO}, \mathrm{Al}_{2} \mathrm{O}_{3}, \mathrm{TiO}_{2}$. Akan tetapi, untuk dapat memaksimalkan penggunaan bahan tersebut, membutuhkan dukungan teknologi baru yakni nanoteknologi.

Bahan oksida khususnya silika $\left(\mathrm{SiO}_{2}\right)$ telah dimanfaatkan dalam berbagai aplikasi. Pemanfaatan silika yang paling familiar dan komersial adalah selain sebagai bahan utama industri gelas, dan kaca juga untuk bahan baku pembuatan sel surya. Baru-baru ini, pemanfaatan silika dan kalsium yang dibuat 
nanokomposit menjadi kandidat bahan bioaktif yang menjanjikan untuk aplikasi perbaikan jaringan tulang (Zhongkui,at al.,2009). Pemanfaatan lain silika orde nano untuk aplikasi di industri yang berkaitan dengan produksi pigmen, pharmaceutical, keramik, dan katalis (Nozawa, at al., 2005).

Bahan silika yang berasal dari alam telah berhasil dimurnikan dan kemudian disintesis hingga menjadi nanosilika. Baru-baru ini telah berhasil diperoleh silika dengan kadar kemurnian tinggi (> $99 \%$ ) dari abu/limbah sampingan industri gula (Samsudin, 2009). Dan telah berhasil disintesis nanosilika dari bahan abu sekam padi dengan kemurnian $98 \%$ dengan menggunakan metode kopresipitasi (Nittaya,at al.,2008) dan dari lumpur sidoarjo (lusi) dengan metode kopresipitasi, kemurnian 95,7\% (Munasir, dkk.,2010), pasir slopeng dengan metode alkalifusi dengan kemurnian 98\% (Munasir, dkk, 2013). Trabelsi berhasil mensintesis silika amorf dari pasir deuriet dengan mereaksikan dengan sodium karbonat $\left(\mathrm{Na}_{2} \mathrm{CO}_{3}\right)$ dengan temperatur pembakaran $1030^{\circ} \mathrm{C}$ (Trabelsi,et al.,2009). Dan Hidetsugu Mori menawarkan metode sintesis dengan menggunakan prinsip kerja membongkar ikatan kimia dalam bahan dengan menggunakan senyawa alkali seperti $\mathrm{KOH}$ dan $\mathrm{NaOH}$ dan kemudian mengikat silikon dioksida $\left(\mathrm{SiO}_{2}\right)$ dari waste colore glasses (Mori, 2003) diperoleh serbuk $\mathrm{SiO} 2$ dengan kemurnian tinggi 99,9\%, metode ini dinamakan metode alkalifusion.

Pada penelitian ini, akan dilakukan sintesis dengan menggunakan metode kopresipitasi, secara prinsip proses ektraksi silika dari bahan dasar pasir kuarsa ada tiga tahapan. Pertama, preparasi sodium silikat $\left(\mathrm{Na}_{2} \mathrm{SiO}_{3}\right)$ dari pasir kuarsa dengan menggunakan $\mathrm{NaOH}$. Kedua, preparasi silicic acid, $\mathrm{Si}(\mathrm{OH})_{4}$, pada tahapan ini, larutan sodium silikat di reaksikan dengan asam kuat $(\mathrm{HCl})$ hingga terbentuk endapan (silika gel) yang masih tercampur dengan $\mathrm{NaCl}$. Karena $\mathrm{Si}(\mathrm{OH})_{4}$ tidak bisa larut dalam asam kuat seperti $\mathrm{HCl}$, $\mathrm{HNO}_{3}$, dan $\mathrm{H}_{2} \mathrm{SO}_{4}$. Maka endapan $\mathrm{Si}(\mathrm{OH})_{4}$ dapat dipisahkan dari larutannya $(\mathrm{NaCl})$. Ketiga, adalah preparasi $\mathrm{SiO}_{2}$ dengan proses pengeringan gel silika $\mathrm{Si}(\mathrm{OH})_{4}$. Metode kopresipitasi ditengarahi mempunyai kelebihan dibanding metode lain dalm mengekstraksi $\mathrm{SiO}_{2}$ orde nano dari bahan anorgonaik, karena pemakaian energi yang cukup rendah $\left(<100^{\circ} \mathrm{C}\right)$ dan berbiaya murah.

\section{BAHAN DAN METODE}

\section{Bahan}

Bahan utama yang digunakan dalam penelitian ini adalah pasir kuarsa yang diambil di daerah Bancar-Tuban Jawa Timur. Dengan kandungan 76,80 wt\% $\quad \mathrm{SiO}_{2}$ (hasil awal uji XRF), larutan $\mathrm{HCl} 37 \%, \mathrm{NaOH} 99 \%$, dan Aquades. Peralatan yang digunakan dalam penelitian ini antara lain adalah gelas beker ukuran 100, 250, 400, dan $800 \mathrm{ml}$; gelas ukur, pipet, spatula logam dan kaca, corong kaca, cawan keramik, mortar, aluminium foil, thermometer, kertas saring, lampu untuk pengeringan, timbangan analitik, furnace dan magnetik stirrer

\section{Metode}

Pasir Tuban di haluskan dan disaring (ukuran homogen) dengan ukuran sekitar 250 mikron. Metode sintesis nanosilika yang digunakan adalah metode basah, yang terdiri dari dua tahap, yaitu: (a) tahap 1 pembentukan larutan sodium silikat $\mathrm{Na}_{2} \mathrm{O} . x \mathrm{SiO}_{2}$ (metode hidrotermal), serbuk pasir kering dicampur dengan larutan senyawa sodium hidrosida $\mathrm{NaOH}$ (7M) dan distirer selama 3-4 jam, sehingga terbentuk larutan sodium silikat. (b) tahap 2 pembentukan bubur silisit $\mathrm{Si}(\mathrm{OH})_{4}$ (metode co-presipitasi), larutan sodium silikat yang telah diperoleh didiamkan sekitar 24 jam, kemudian diputar distirer sambil dititrasi dengan $\mathrm{HCl}(2 \mathrm{M})$ sehingga $\mathrm{pH}$ larutan mendekati netral (PH 6-7) dan mulai terbentuk larutan keruh ( $\mathrm{sol}$ ) dan terbentuk gel berwarna putih/ bubur silisit disaring dengan kertas saring dan dilakukan pencucian dengan air yang terionisasi (DI water) beberapa kali untuk membersihkan sisa-sisa $\mathrm{NaCl}$ yang mungkin masih ada di gel. Endapan $\mathrm{Si}(\mathrm{OH})_{2}$ (silica gel) didiamkan kemudian di keringkan dengan menggunakan cahaya lampu $100 \mathrm{~W}$ selama 2 hari. Silika gel $\left(\mathrm{SiO}_{2}\right)$ selanjutnya diuji XRD, XRF, FTIR dan SEM.

\section{HASIL DAN DISKUSI}

\section{Hasil}

\section{Analisis XRF}

Hasil uji XRF yang dilakukan pada sampel pasir silika yang diambil di lokasi penambangan pasir Bancar Tuban Jawa Timur Indonesia, diperoleh hasil seperti pada tabel 1 , unsur atom dan senyawa oksida dalam persentase massa (\%). 
Tabel 1. Hasil analisis Data XRF Sampel Pasir dan nanosilika NS-1, NS-2, dan NS-3 hasil sintesis denganNaOH bervariasi berturut-turut: $5 \mathrm{M}, 6 \mathrm{M}$ dan $7 \mathrm{M}$

\begin{tabular}{|c|c|c|c|c|}
\hline \multirow{2}{*}{ Sampel } & \multicolumn{4}{|c|}{ Unsur atom (\%wt) } \\
\cline { 2 - 5 } & $\mathbf{S i}$ & $\mathbf{C a}$ & $\mathbf{K}$ & lainya \\
\hline Pasir-BT & 69,30 & 7,50 & 4,80 & $<1,00$ \\
\hline NS & 95,00 & 1,00 & 0,16 & $<1,00$ \\
\hline C-Silgel & 98.00 & 1.10 & 0.33 & 0.57 \\
\hline
\end{tabular}

Tampak dari tebel 1, bahwa unsur kimia yang terdapat pada sampel pasir silika dilokasi Bancar-Tuban mempunyai unsur kimia mayoritas ( $\mathrm{Si}, \mathrm{Ca}$ dan $\mathrm{K}$ ) dan senyawa oksida mayoritas $\left(\mathrm{SiO}_{2}, \mathrm{CaO}\right.$ dan $\left.\mathrm{Fe}_{2} \mathrm{O}_{3}\right)$ yang terkandung didalamnya. Tampak pula bahwa hasil sintesis nanosilika (NS-3) dengam molaritas $\mathrm{NaOH} 7 \mathrm{M}$ dan $\mathrm{pH}$ titrasi 7-8, diperoleh prosentase $\mathrm{Si}$ yang meningkat dari $69,30 \mathrm{wt} \%$ menjadi $95,0 \%$ wt.

\section{Analisis XRD}

Hasil uji Difraksi Sinar-X terhadap sampel pasir Tuban, Jawa Timur, Indonesia , menunjukan bahwa bidang kristal (peak) didominasi oleh quartz dan calsite. Hasil search-match data difraksi sinar-x (pasir Bancar-Tuban) yang belum dilakukan treatmnt, menunjukan bahwa peak yang muncul dominan

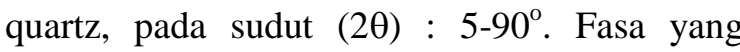
teridentifikasi ada dua, yaitu quartz, dan calcite. Quartz merupakan salah satu fasa kristal dari $\mathrm{SiO}_{2}$ selain trydymite dan crystobalite. Intensitas $100 \%$ berada pada posisi $2 \theta=26,61^{\circ}$ dan teridentifikasi sebagai fasa quartz. (Munasir, 2010).

Adapun pola difraksi sinar-X hasil sintesis nanosilika dengan metode copresipitasi, molaritas $\mathrm{NaOH}$ bervariasi $(5-7 \mathrm{M})$ dengan titrasi pH 7-8, diperlihatkan pada gambar 2. Pada molaritas $7 \mathrm{M}$ terbentuk puncak kristalin fase quartz didalam fase amorf. Dan tampak pola difraksi yang menunjukkan pergeseran posisi puncak. Hal ini dimungkinkan terjadi karena $\mathrm{SiO}_{2}$ mulai terbentuk pada $\mathrm{pH}$ netral $\sim 7$ 8 kemudian proses titrasi dihentikan, sehingga dimungkinkan masih banyaknya impuritas yang belum tereduksi sempurna.

Molaritas $\mathrm{NaOH}$ juga berperan besar dalam proses pembentukan sodium silikat
$\left(\mathrm{Na}_{2} \mathrm{SiO}_{3}\right)$ untuk menghasilkan $\mathrm{SiO}_{2}$. Pada molaritas $5 \mathrm{M}$ terlihat perbedaan puncak dengan molaritas $\mathrm{NaOH} 6 \mathrm{M}$ dan $7 \mathrm{M}$. Hal ini disebabkan tidak seluruhnya $\mathrm{SiO}_{2}$ bereaksi dengan $\mathrm{NaOH}$ untuk membentuk $\mathrm{Na}_{2} \mathrm{SiO}_{3}$ secara menyeluruh. Sehingga menyebabkan karakter puncak dari molaritas $5 \mathrm{M}$ bergeser seperti terlihat pada Gambar 1.

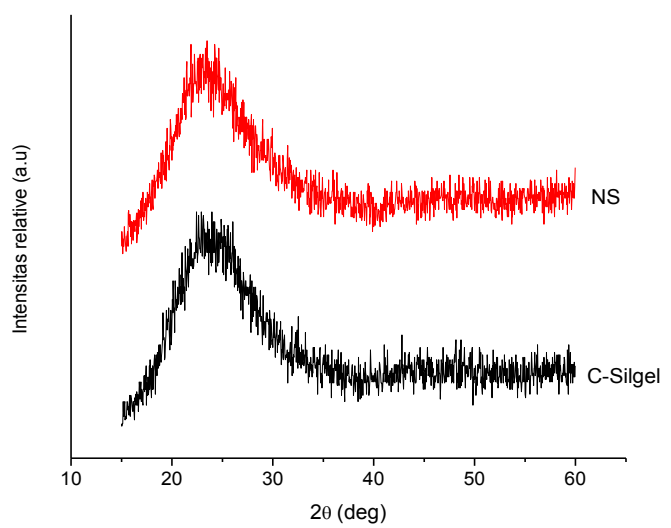

Gambar 1. Pola difraksi sinar-X serbuk nanosilika hasil sintesis (7 $\mathrm{M} \mathrm{NaOH} \& \mathrm{pH} 7$ )

\section{Analisis FTIR}

Pola serapan vibrasi gelombang yang terbentuk dianalisis untuk mengetahui dengan jelas gugus fungsi yang telah terbentuk dari sampel yang telah diuji. Tampak hasil uji sampel pada gambar 2 .

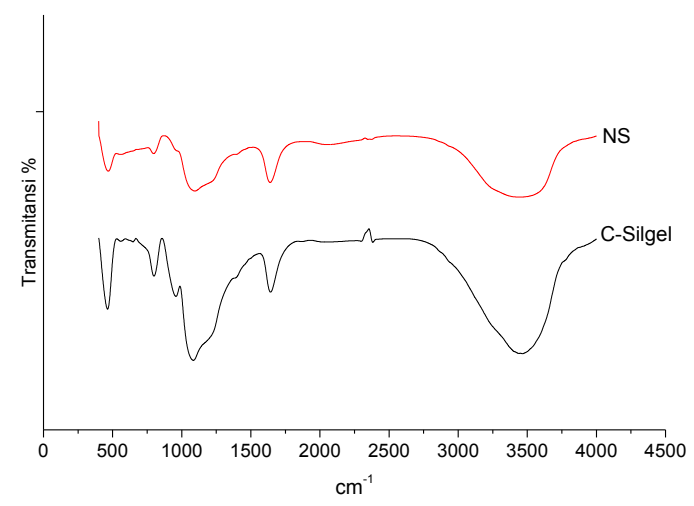

Gambar 2. Pola FTIR serbuk nanosilika hasil sintesis (7 M NaOH \& pH7)

Posisi puncak serapan bilangan gelombang $465-475 \mathrm{~cm}^{-1}, 800-870 \mathrm{~cm}^{-1}$ dan $3000-4000 \mathrm{~cm}^{-1}$ menunjukkan pola serapan dari gugus fungsi $\mathrm{Si}-\mathrm{O}$, gugus $\mathrm{OH}$ dari $\mathrm{SiO}$, dan gugus $\mathrm{O}-\mathrm{H}$ (PK, Jal, 2004). Pola serapan gugus $\mathrm{Si}-\mathrm{O}-\mathrm{Si}$ (siloksan) yang mempunyai rentang 
frekuensi antara 1050-1115 $\mathrm{cm}^{-1}$. Pada semua sampel hasil sintesis terjadi pergeseran ke bilangan gelombang serapan NS yang lebih rendah dibandingkan bilangan gelombang $\mathrm{C}$ Silgel $\left(1114 \mathrm{~cm}^{-1}\right)$, yaitu: $1109 \mathrm{~cm}^{-1}$. Hal ini diduga diakibatkan oleh adanya perubahan lingkungan gugus $\mathrm{Si}-\mathrm{O}-\mathrm{Si}$ (siloksan) yang merupakan hasil kondensasi antara anion silikat dengan gugus silanol. Pola gugus fungsi $\mathrm{O}-\mathrm{H}$ (molekul air) yang mempunyai serapan pada bilangan gelombang $1639 \mathrm{~cm}^{-1}$ juga mengalami pergeseran ke bilangan gelombang serapan yang lebih rendah yaitu: pada silika komersial $\left(1624 \mathrm{~cm}^{-1}\right)$, NS $\left(1619 \mathrm{~cm}^{-1}\right)$.

\section{Produksi $\mathrm{SiO}_{2}$}

Ada kecenderungan produk silika orde nano yang diperoleh pada pada $\mathrm{pH}$ 7-8 mengalami mengalami peningkatan untuk molaritas $\mathrm{NaOH}$ semakin besar. Massa serbuk nanosilika yang dihasilkan dengan metode kopresipitasi dengan molaritas $\mathrm{NaOH}(7 \mathrm{M})$ saat proses ekstraksi $\mathrm{SiO}_{2}$ melalui pembentukan senyawa $\mathrm{Na}_{2} \mathrm{SiO}_{3}$ fase padat dan larutannya . Pada $\mathrm{NaOH} 7 \mathrm{M}$ dengan $\mathrm{pH}$ titrasi 7-8 diperoleh prosentasi nanosillika $41,355 \%$ dari sekitar 4 gram serbuk pasir.

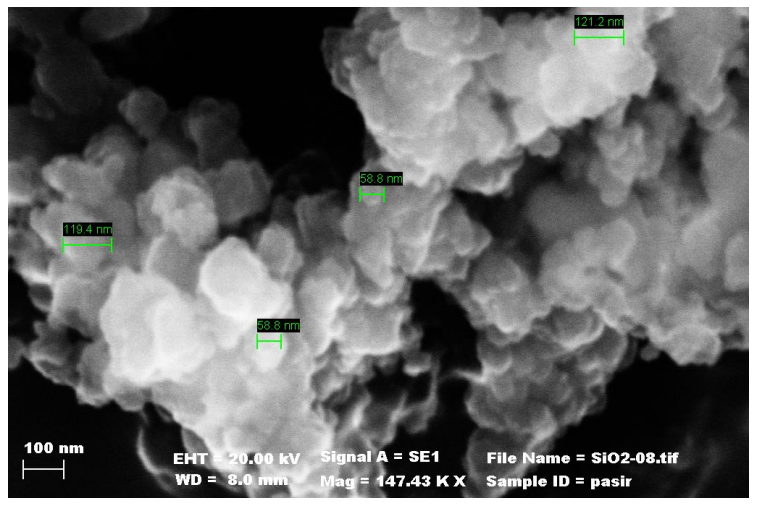

Gambar 3. Profil struktur mikro (hasil uji SEM) serbuk nanosilika hasil sintesis, (NS).

\section{Analisis SEM}

Hasil analisis SEM untuk Nanosilika hasil sintesis ditunjukan pada gambar 3 . Berdasar hasil pengamatan SEM dapat dilihat partikel $\mathrm{SiO}_{2}$ ukuran $\sim 100 \mathrm{~nm}$ dapat teramati walaupun sebagian besar tampak kumpulan partikel-partikel kecil yang menyatu membentuk partikel besar (beraglomerasi).
Hal ini sebenarnya sudah dapat diprediksikan sebelumnya dengan melihat hasil XRD dimana sampel tersebut adalah salah satu sampel yang terbentuk kristal quartz dari hasil XRD serta search match yang dilakukan. Sampel ini mempunyai puncak-puncak yang intensitasnya tidak terlalu tinggi tetapi melebar, dimana hal itu merupakan salah satu karakteristik dari material yang berukuran nano.

\section{Diskusi}

Pencampuran serbuk pasir kuarsa dengan larutan $\mathrm{NaOH}$ yang diaduk sambil dipanaskan dengan temperatur $80^{\circ} \mathrm{C}$, senyawa $\mathrm{NaOH}$ terdisosiasi sempurna membentuk ion $\mathrm{Na}^{+}$dan ion hidroksida $\mathrm{OH}^{-}$. Sedangkan $\mathrm{SiO}_{2}$ dalam serbuk pasir akan mengalami pembentukan ion intermediet $\left(\mathrm{SiO}_{2} \mathrm{OH}\right)^{-}$yang tidak stabil. Dalam $\mathrm{SiO}_{2}$ elektronegatifitas $\mathrm{O}$ lebih tinggi sehingga menyebab-kan $\mathrm{Si}$ lebih elektropositif. Selanjutnya akan terjadi proses hidrogenasi dan ion hidroksil yang berikatan dengan hidrogen membentuk molekul air dan dua ion $\mathrm{Na}^{+}$yang akan menetralkan muatan negatif yang terbentuk, berinteraksi dengan ion $\mathrm{SiO}_{3}{ }^{2-}$ hingga terbentuk sodium silikat $\left(\mathrm{Na}_{2} \mathrm{SiO}_{3}\right)$ [Munasir,2013]. Pada proses ini sodium silikat yang diperoleh berbentuk padat, selanjutnya dengan penambahan aquades $\left(\mathrm{H}_{2} \mathrm{O}\right)$ akan diperoleh larutan sodium silikat, yang selanjutnya berfungsi sebagai precursor pada pembentukan silika gel $\left(\mathrm{SiO}_{2}\right)$. Larutan sodium silikat diputar dengan hotplate stirer dengan temperatur $70^{\circ} \mathrm{C}$ sambil diteteskan $2 \mathrm{M} \mathrm{HCl}$ hingga $\mathrm{pH}$ 7. Pada proses ini terjadi peristiwa pembentukan gugus siloksi $\left(\mathrm{Si}^{-} \mathrm{O}^{-}\right)$dan gugus silanol (Si-OH), selanjutnya gugus silanol berinteraksi dengan gugus siloksi hingga terbentuk gugus siloksan $(\mathrm{Si}-\mathrm{O}-\mathrm{Si})$ proses ini terjadi sangat cepat hingga terbentuk silika gel dengan produk sampingan $\mathrm{NaCl}$. Selanjutnya proses anging dan proses penetralan atau membuang $\mathrm{NaCl}$ dengan aquades $\left(\mathrm{H}_{2} \mathrm{O}\right)$.

Penggunaan variasi molaritas dan $\mathrm{pH}$ akhir saat titrasi ternyata menghasilkan sampel yang berbeda. Sampel yang dihasilkan ternyata sebagian kecil mulai terbentuk kristal dimana fase yang teridentifikasi yaitu quartz. Molaritas $\mathrm{NaOH}$ dan $\mathrm{pH}$ pada penelitian ini berfungsi sebagai driving force dalam pembentukan kristal [Munasir, 2012]. Pembentukan fasa biasanya menggunakan perlakuan suhu tinggi, sehingga cukup banyak membutuhkan 
konsumsi energi srta membutuhkan waktu yang lama. Melalui metode kopresipitasi hanya membutuhkan waktu sampai terbentuknya sampel kurang dari 4 jam. Dengan demikian jika dibandingkan dengan metode lain yang biasa digunakan untuk mengekstrak pasir atau limbah gelas menjadi nanosilika, metode ini jauh lebih hemat, demikian halnya dengan mulai terbentuknya fase kristal (fase quartz) ini tidak dijumpai dalam metode alkali fusion (Mori, 2003) Jika dilihat dari morfologi SEM teramati ukuran partikel dalam skala kurang dari $100 \mathrm{~nm}$ untuk sampel dengan $\mathrm{pH} \sim 7-8$ dengan molaritas $7 \mathrm{M}$, sehingga dapat disimpulkan bahwa sampel ini merupakan $\mathrm{SiO}_{2}$ kristal dalam lautan amorf.

\section{KESIMPULAN DAN SARAN \\ Kesimpulan}

Beberapa kesimpulan yang bias ditarik dari hasil penelitian ini, bahwa:

Telah dapat disintesis serbuk nanosilika dari bahan dasar bahan alam (pasir Bancar) dengan metode sederhana dan murah, yaitu metode basah yang merupakan gabungan dari metode hidrotermal sebagai tahap pembentukan prekursor sodium silikat $\left(\mathrm{Na}_{2} \mathrm{O} . x \mathrm{SiO}_{2}\right)$, dan metode co-presipitasi sebagai tahap pembentukan bubur silisit (slurry silicite) $\mathrm{Si}(\mathrm{OH})_{4}$.

Variasi molaritas $\mathrm{NaOH}$ pada proses ekstraksi $\mathrm{SiO}_{2} \quad$ berpengaruh terhadap pembentukan fase yang terbentuk, nanosilika amorf dan nanosilika kristal (fase quartz) yang mulai terbentuk, hal ini tampak pada pola difraksi sinar-X pada sampel yang dipreparasi dengan $7 \mathrm{M} \mathrm{NaOH}$.

Variasi molaritas $\mathrm{NaOH}$ pada proses ekstraksi dan $\mathrm{pH}$ henti saat titrasi berpengaruh terhadap produksi dan struktur mikro (particles size) nanosilika yang dihasilkan, pada $7 \mathrm{M}$ $\mathrm{NaOH}$ dengan $\mathrm{pH}$ akhir titrasi 7 (netral) ukuran partikel $\mathrm{SiO}_{2}$ sekitar $\sim 58 \mathrm{~nm}$.

\section{Ucapan Terima Kasih}

Disampaikan terimaksih yang setinggitingginya kepada Kementrian Pendidikan Nasional melalui DIKTI, yang telah memberikan support financial kepada penulis melalui Program Beasiswa Pascasarjana (BPPS) selama menyelesaiakan Program S3 di Prodi S3 Fisika ITS Surabaya.

\section{DAFTAR PUSTAKA}

W. Trabelsi, M. Benzina , S. Bouaziz, 2009. Physico-chemical characterisation of the Douiret sand (Southern Tunisia): Valorisation for the production of Silica Gel, Physics ysics Procedia 2 (2008) 1461-1467.

Sang-Wook Ui, Seung-Jae Lim, Sang-Hoon Lee and Sung-Churl Choi ,2009. Control of the size and morphology of nano-size silica particles using a sodium silicate solution. Journal of Ceramic Processing Research. Vol. 10, No. 4, pp. 553 558 .

Jerzy Chruściel, L. Ś. (2003). "Synthesis Of Nanosilica By The Sol-Gel Method And Its Activity Toward Polymers." Materials Science 21 (4)(Nano Silica): 7.

Nuntiya, N. T. A. A. (2008). "Preparation Of Nanosilica Powder From Rice Husk Ash By Precipitation Method." Chiang Mai J. Sci. 2008; 35(1) : 206-211 35 (1)(Nano Silica): 6.

Morri, Heditsugu. Extraction of Silicon Dioxide from Waste Colored Glasses by Alkali Fusion Using Sodium Hydroxide. Journal of The Ceramic Society of Japan.111 (6).(2003): 376-381.

Morri, Heditsugu. Extraction of Silicon Dioxide from Waste Colored Glasses by Alkali Fusion Using Potasium Hydroxide. Journal of The Ceramic Society of Japan.38 2003): 3461-3468.

M. Waseem, S. Mustafa, A. Naeem, K. H. Shah, Irfan Shah And Ihsan-Ul-Haque: Synthesis And Characterization Of Silica By Sol-Gel Method. J Pak Mater Soc 20093 (1)

Munasir, Ahmad Mirwan Abdullah, Triwikantoro, 2010. Sintesis Silika Amorf Dari Bahan Alam Lumpur Sidoarjo dengan Metode Kopresipitasi, Prosiding Seminar Nasional UNNES Semarang.

Munasir, Sulton A, Triwikantoro, M. Zainuri, Darminto., (2013). Synthesis of Silica Nanopowder from Slopeng Natural Sands via Alkalifussion Route., AIP Conf. Proc. 1555, 28 (2013); doi: 10.1063/1.4820986

P.K. Jal , M. Sudarshan, A. Saha, Sabita Patel, B.K. Mishra ,. (2004). "Synthesis and characterization of nanosilica prepared by precipitation method." Colloids and Surfaces A: Physicochem. Eng. Aspects 240: 6. 
Samsudin Affandi, Heru Setyawan, Sugeng Winardi, Agus Purwanto, Ratna Balgis . A Facile Method For Production Of HighPurity Silica Xerogels From Bagasse Ash. Advanced Powder Technology 20 (2009) 468-472

Van, Hoek., Winter, R., 2002. "Amorphous silica and the intergranular structure of nanocrystalline silica ". Phys Chem Glass 43C 80.

Yasuhiko Arai, Hiroyo Segawa ,Kazuaki Yoshida. Synthesis Of Nano Silica Particles For Polishing Prepared By Sol-Gel Method. Journal Of Sol-Gel Science And Technology 32, (2004) 79-83 